\title{
An Analysis of English Learning Barriers of Minority Preparatory Students and its Strategies
}

\author{
Fuxia $\mathrm{Li}^{1}$, Huifang $\mathrm{Ma}^{1}$, Lidong Wang,** \\ ${ }^{1}$ School of Foreign Languages, Dalian Nationalities University, Liaoning province, China \\ ${ }^{2}$ School of Science, Dalian Nationalities University, Liaoning province, China \\ *Corresponding author: wld0707@163.com
}

Received August 03, 2013; Revised August 15, 2013; Accepted August 16, 2013

\begin{abstract}
Our nation is a multi-ethnic nation with 55 minorities, and 53 of them use their native language. Most preparatory students will inevitably be influenced or interfered, more or less, by their native languages, cultures, customs, cognitive and non-cognitive factors. In this essay, we are going to carry out an investigation of English learning barriers of minority preparatory students and a brief discussion of its strategies, aiming to educate them to meet their own needs in preparatory teaching and provide some effective learning approaches for preparatory students.
\end{abstract}

Keywords: minority, preparatory students, preparatory teaching, English learning barriers, strategies

Cite This Article: Fuxia Li, Huifang Ma, and Lidong Wang, "An Analysis of English Learning Barriers of Minority Preparatory Students and its Strategies.” American Journal of Educational Research 1, no. 7 (2013): 267-271. doi: 10.12691/education-1-7-9.

\section{Introduction}

English teaching and language learning is a bi-lateral activity between teachers and students, which interacts on each other via teachers' teaching and students' learning with the medium of English textbooks. It facilitates their acquisition of English language, improves their capabilities, develop their characters and forge a positive learning attitude.

The goal of English education is ultimately reflected by students themselves, therefore, for the sake of ideal learning outcomes, not only should textbooks, teaching means and methods be complied with students' learning rules of preparatory English learning, but also we should probe into their cultural conflicts, psychological traits, ethnic thinking modes, cognitive modes and their learning motivation in the learning process. As a result, the prime problem which is a core issue to improve English learning efficiency of minority preparatory students is how to acquire English knowledge, skills and capabilities and find out the rules, in the current stage where students have adapted themselves to the college learning environment. In this essay, our research purpose is to know what minority preparatory students' English learning barriers are in the current stage well by designing questionnaires and a survey according to students' English learning motivations, influence of family factors and influence of teachers' attitudes and teaching level, then we analyze and discuss to find out methods and strategies which are more appropriate for them to learn English, to overcoming their learning barriers, to raise their English learning ability effectively.

\section{Objective}

Systematically speaking, preparatory English learning is a system, and the research of it is to explain what interrelated and interactive elements comprise this system. As system is not simply piled up by the elements, we have to make a comprehensive research of English learning, from the systematic view, combining each element and their interaction together. According to the theories of modern cognitive psychology [1], English learning process of minority preparatory students, an interrelated activity of both the newly-learnt English knowledge and their original related knowledge in the cognitive structure, is to form new English cognitive structure or expand the original structure. In addition, due to the differences in geographic regions and ecological environment, minorities have formed a relatively independent lifestyle and traditional customs. Besides their formation of the distinctive cultures, they have set up the inner psychological mode, like their own ethnic thinking modes and cognitive modes. The psychology of minority students is formed when minorities with different cultural background have been living in their isolated areas. This innate ethnic psychology partly leads to a character of hesitation when minority preparatory students are facing the new environment, and thereby a psychological barrier in the English classes, which is reflected in being afraid to make mistakes, speak out and answer questions. This phenomenon indicates the psychological conflicts, caused by innate psychological cognitive modes before new things, are demonstrated by inadaptability of thinking modes and emotional expressions to the social background, 
and inadaptability to the new requirements in the new environment. This fully proves that the psychology of English learning for minority preparatory students is not merely a cognitive process, but also a process mingled with emotion, determination, environment and psychological traits. Some of them cannot be a direct part of cognitive activities of English learning, but they indeed facilitate and govern the learning process. It can be seen that English learning of minority preparatory students is greatly influenced by their own cognitive and noncognitive factors. Meantime, English learning could facilitate the development of cognitive and non-cognitive factors, while cognitive and non-cognitive factors could interact with each other. All these three aspects interrelate and interact, which make up the learning system of preparatory students.

English learning of preparatory students is a dynamic system, and the cognitive and non-cognitive factors it embraces will be changed with passage of time, environment, and development of psychology and thinking mode. Thinking mode development has an intimate relationship with English learning of preparatory students. By virtue of different levels of their psychology and thinking mode development, there must be significant divergence in English learning.

English learning of preparatory students is an open system as well [2], and for the sake of its improvement, it constantly exchange with the outer world for "energy", "information" and the like. The outer world here refers to the ethnic customs of preparatory students, school environment, western cultural mind, family, parents, teachers and peers, and the latter four of which are the most influential to their English learning. We assume, on the basis of our research, that the motivations of learning English among preparatory students derive from parents' expectations, teachers' model role, encouragement and help from their peers, social needs and their interest in English knowledge. Therefore, when discussing the English learning of preparatory students, we should not only have a research on the system composed of their own learning activities, cognitive and non-cognitive factors, but also a research on the organic interrelation, interaction and interplay between this system and the outer world.

\section{Method}

From the discussion above, the cognitive activities of their English learning include their current thinking capability, cognitive and non-cognitive factors, family's influence, teachers' model role, social needs, emotional feelings and determination as well as their original structure of English knowledge.

To get a deeper insight of the factors that influence barriers of English learning among minority preparatory students and get a better exploration of the effectiveness of their English learning, this research was conducted among minority preparatory students enrolled in 2012, among which the Uygurs and the Kazakhs took up20\%, the Koreans $10 \%$, the Mongols $20 \%$, rare ethnic people $10 \%$ and other minorities 40\%. 203 questionnaires were distributed in this research, and all the 203 valid questionnaires were collected.

\section{Results}

\subsection{Students' Motivations to Learn English}

Motivation is referred to a kind of internal incentive that motivates and spurs students' learning. The learning motivation of students comes from a need of learning, whereas, need generally is a pursuit in psychology. As need cannot be fulfilled for the time being, it urges the learners to release certain amount of energy and make efforts to satisfy this need, and in this circumstance, need arouses motivation of learning.

Different needs may produce different motivations and Maslow once classified needs into five hierarchies,

(1) physiological needs

(2) safety needs

(3) love and belonging needs

(4) esteem needs

(5) self-actualization

Different hierarchies correspond to different motivations. Learning motivations could be classified into external and internal motivations. The learning motivations, aroused by a good major, a good job and the post-graduate study for preparatory students, are external motivations. Whereas the learning motivations, for improving interest, enriching knowledge and understanding foreign cultures are internal motivations. Comparatively speaking, internal motivations enable a higher and longer learning efficiency.

Concerning the motivations of preparatory students, it is essential to mention the purpose of preparatory study, for they differentiate and correlate with each other. The target of learning is to advance into the college study and choose an ideal major. The motivations of learning English are incentives for preparatory students to achieve targets. As a matter of fact, the motivations for them to learn English are diverse.

Table 1. Motivations to Learn English

\begin{tabular}{|l|c|}
\hline 1) usefulness of English (29.3\%) & $\begin{array}{c}\text { 2) interest in English learning } \\
(14.7 \%)\end{array}$ \\
\hline $\begin{array}{l}\text { 3) prime course for college } \\
(13.8 \%)\end{array}$ & $\begin{array}{c}\text { 4) access to an ideal major } \\
(15.9 \%)\end{array}$ \\
\hline $\begin{array}{l}\text { 5) imposition from parents and } \\
\text { teachers (2.5\%) }\end{array}$ & $\begin{array}{l}\text { 6) future job as English major } \\
(3.0 \%)\end{array}$ \\
\hline 7) for overseas study (8.9\%) & 8) for post-graduate study (7.0\%) \\
\hline $\begin{array}{l}\text { 9) for appreciation of foreign } \\
\text { culture (4.9\%) }\end{array}$ & \\
\hline
\end{tabular}

\subsection{Influence of Family Factors}

Family is the first place where students receive education, therefore, the factors, such as living environment and family's economic status, parents' educational background, and parents' expectations of their children, will lay positive, negative and various limitations on students' learning. The influential factors on students from the family include:

(1) degree of parents' education

(2) occupation

(3) economic conditions

(4) expectations of their children

(5) attitudes towards children

(6) learning atmosphere in family

(7) influence of ethnic language on English learning

(8) influence of ethnic cultures, customs and traditions on English learning 
Table 2. Educational Background of Students' parents

\begin{tabular}{|c|c|c|c|}
\hline & $\begin{array}{c}\text { Higher } \\
\text { education }\end{array}$ & $\begin{array}{c}\text { Secondary } \\
\text { education }\end{array}$ & $\begin{array}{c}\text { Primary } \\
\text { education or } \\
\text { illiterate }\end{array}$ \\
\hline $\begin{array}{c}\text { The proportion of top } \\
\text { students in the survey }\end{array}$ & $50 \%$ & $47.2 \%$ & $43.6 \%$ \\
\hline $\begin{array}{c}\text { The proportion of } \\
\text { lower-level students } \\
\text { in the survey }\end{array}$ & $50 \%$ & $52.8 \%$ & $56.4 \%$ \\
\hline
\end{tabular}

Table 3. Occupation of Students' parents

\begin{tabular}{|c|c|c|c|}
\hline & $\begin{array}{c}\text { Teachers, } \\
\text { doctors, } \\
\text { engineers or } \\
\text { other } \\
\text { intellectuals }\end{array}$ & $\begin{array}{c}\text { Civil servants or } \\
\text { leaders of } \\
\text { government } \\
\text { institutions }\end{array}$ & $\begin{array}{c}\text { Workers or } \\
\text { other blue- } \\
\text { collars } \\
\text { labors }\end{array}$ \\
\hline $\begin{array}{c}\text { The proportion } \\
\text { of top students } \\
\text { in the survey }\end{array}$ & $52.5 \%$ & $44.4 \%$ & $43.6 \%$ \\
\hline $\begin{array}{c}\text { The proportion } \\
\text { of lower-level } \\
\text { students in the } \\
\text { survey }\end{array}$ & $47.5 \%$ & $55.6 \%$ & $56.4 \%$ \\
\hline
\end{tabular}

Table 4. Degree and Manner of Parents' consideration

\begin{tabular}{|c|c|c|c|c|}
\hline & $\begin{array}{c}\text { Great } \\
\text { consideration } \\
\text { and agreeable } \\
\text { manner }\end{array}$ & $\begin{array}{c}\text { no agreeable } \\
\text { manner of } \\
\text { consideration }\end{array}$ & $\begin{array}{c}\text { No much } \\
\text { consideration }\end{array}$ & $\begin{array}{c}\text { Never } \\
\text { care }\end{array}$ \\
\hline $\begin{array}{c}\text { Top } \\
\text { students }\end{array}$ & $50.2 \%$ & $29.2 \%$ & $0 \%$ & $0 \%$ \\
\hline $\begin{array}{c}\text { Lower- } \\
\text { level } \\
\text { students }\end{array}$ & $49.8 \%$ & $70.8 \%$ & $0 \%$ & $0 \%$ \\
\hline
\end{tabular}

Table 5. Family atmosphere

\begin{tabular}{|c|c|c|c|}
\hline & $\begin{array}{c}\text { frequent reading } \\
\text { by parents }\end{array}$ & $\begin{array}{c}\text { rare reading by } \\
\text { parents }\end{array}$ & $\begin{array}{c}\text { No reading by } \\
\text { parents }\end{array}$ \\
\hline Top students & $50 \%$ & $48.3 \%$ & $38.7 \%$ \\
\hline $\begin{array}{c}\text { Lower-level } \\
\text { students }\end{array}$ & $50 \%$ & $51.7 \%$ & $61.3 \%$ \\
\hline
\end{tabular}

Notes: (1) The criterion of top students: the score is above 75 in the written examination, during the class they can answer and ask questions in English actively, they are able to communicate easily in English. (2) The criterion of average students: The score is 40 between 75 the written examination, during the class they can answer and ask questions in English actively, they are able to communicate in English with teachers' encouragement. (3) The criterion of students below average level: the score is less than 40 in the written examination, usually they can't speak English at all.

\subsection{Influence of School Factors}

The influence of teaching style on English learning of preparatory students

\begin{tabular}{|c|c|c|c|} 
Table 6. Your favorite teacher \\
\begin{tabular}{|c|c|c|c|}
\hline $\begin{array}{c}\text { Interesting and } \\
\text { vivid teaching }\end{array}$ & $\begin{array}{c}\text { Gentle } \\
\text { but strict }\end{array}$ & $\begin{array}{c}\text { Fair and } \\
\text { well- } \\
\text { behaved }\end{array}$ & $\begin{array}{c}\text { Responsible and } \\
\text { caring for students }\end{array}$ \\
\hline $52.4 \%$ & $18.4 \%$ & $3.7 \%$ & $25.5 \%$ \\
\hline
\end{tabular}
\end{tabular}

As is shown in Table 1, "usefulness of English", "access to an ideal major", "prime course for college", "imposition from parents and teachers", "for post-graduate study", and "for overseas study" belong to the external motivations of preparatory students; "interest in English learning", "future job as English major", and "for appreciation of foreign culture" belong to the internal motivations. According to the statistics, the external motivations (77.4\%) of English learning of preparatory students greatly outweigh the internal motivations (17.7\%). There is no strong internal learning motivation, and most of the students aim to cope with exams, which leads to a negative and passive attitude towards acquiring knowledge, and thereby a lack of enthusiasm to communicate voluntarily with the outer world.

Table 2 indicates that parents' educational background is influential to the level of students' English learning. The proportion of educational background of top students' parents decreases from higher education (50\%) to primary education or illiterate (43.6\%); whereas, the proportion of educational background of lower-level students' parents shows an increasing tendency, from higher education (50\%) to primary education or illiterate (56.4\%).

Table 3 reports that the proportion of occupations "intellectuals" and "leaders of the government or institutions" of top students' parents is higher than that of "labor workers"; whereas the occupation of "labor workers" among lowerlevel students' parents takes up the largest proportion.

Table 4 demonstrates that parents of top students mostly show great consideration to their kids in an agreeable way, which constitutes 50.2\%; whereas parents of lower-level students show relatively less care to their kid in a less agreeable way, which constitutes $70.8 \%$.

Table 5 presents that top students' parents take much more time to do reading, thereby a proportion of \% of frequent reading; while, the highest proportion (61.3\%) lies in "no reading by parents" among parents of poor English learners.

As discussed above, parents' degree of education and occupation have an influence on their own acquisition of information, understanding and judgment of the outer world. This causes the differences in their expectations of children's learning, plus differences in the way and frequency of their consideration and encouragement to children. Ultimately these differences take a certain effect on students' learning outcomes.

Table 6 we can see clearly from the survey that preparatory students show their respect to teachers and they are preferable to the teachers whose classes are vivid and interesting. And teachers, in English learning of preparatory students, play an extremely significant role in students' grasp of English knowledge, development of capability, formation of a positive attitude and cultivation of English learning interest. Therefore, English teachers are loaded with more important responsibilities for preparatory students.

As it is analyzed above we get the following conclusion:

(1) external factors influence students more than their own motivations.

(2) parents influence their children getting information, influence their children outstanding and judgment of the world and societies greatly.

(3) teachers' teaching methods, level and their emotion intelligence are very important, too.

\section{Discussion}

As we can see from the above survey and analysis, the learning motivations are varied of minority preparatory 
students, including direct motivations (interest in English learning), and indirect motivations (comprehension of western cultures via English learning). However, the learning barriers of preparatory students are diverse as well; therefore, we put forward the following strategies to address the English learning barriers of preparatory students.

(1) We have to make psychological analysis of their English learning

(2) We have to make an exploration of their cognitive and non-cognitive factors.

(3) We have to make an understanding of environmental factors (family background and teachers' influence), ethnic cultures and traditional customs.

\subsection{Strengthen the Communications among Preparatory Students, Boost the Integration of Ethnic Cultures and Overcome the Psychological Conflicts}

On account of divergence in living regions and ecological environment of preparatory students, each ethnic group has formed a relatively independent lifestyle, traditional customs, and thereby the distinctive features of ethnic consciousness and ethnic cognitive mode. With shift in environment after college, there will be a lack of communication and psychological inadaptability among minority students due to their unavoidable psychological conflicts; as a result, as teachers of preparatory students, we have to draw attention to the psychological difference of preparatory students and improve their learning efficiency by modifying their psychological status. The principles we have to comply with are as follows:

(1) Respect for ethnic cultures

(2) Emotional factors and removal of psychological barriers

(3) Cross-cultural principle of students' cultivation

(4) Rules of learning ABCs of listening and speaking

(5) Rules of taking communicative content into consideration

(6) Cognitive rules. Minority preparatory students are expected to make a comparison between the structure of English and that of their native language, have a deeper understanding of the systematic knowledge of English language, improve their learning strategies and memorizing skills, take their initiative and cultivate the positive learning habit and methods.

\subsection{Assist Preparatory Students to Overcome the Language Barriers}

Our nation is a multi-ethnic nation with 55 minorities groups, 53 of them use their native language [1]. Most preparatory students will inevitably be influenced or interfered, more or less, by their native language, culture and pronunciation. The difficulty in learning English pronunciation for preparatory students resides in the fact that different languages have different morphemes, and some morphemes in some language cannot be found in another. Therefore, teachers for preparatory students should highlight this point to students least they should stick to their own native way of pronunciation which is supposed to be great barrier to learning English pronunciation.
For example, it's difficult to pronounce the sounds [n], [1]for minorities students in Hunan, Guizhou, Sichuan Province and southwest regions, while minorities students in northern part of our nation find it hard to pronounce[s], [z]. Teachers of preparatory students accordingly should correct their pronunciations in time in accordance with their own pronunciation features.

\subsection{Take Advantage of their Ethnic Languages and Customs to Enlarge English Vocabulary}

English language has a considerable amount of aliens from Latin and French and many borrowed words from Chinese and Arabic; minority languages have borrowed a lot from English meanwhile. Therefore, if teachers of preparatory students could make a clear comparison between aliens and native languages, adopting a wordclassification method in the teaching process, it is undoubtedly beneficial for preparatory students to understand and memorize the vocabulary in an easy way. Furthermore, teachers will achieve multiplier effect if they combine the ethnic customs and English teaching together.

\subsection{Research Teaching Methodology and Boost the Art of Teaching Course}

English learning of preparatory students is represented by a succession of psychological activities, which are carried out by teachers' help and guidance, and consequently teachers' English knowledge, experience, art of teaching, and popularity with students will lay a direct influence on students' English learning outcome. Teachers' character and teaching art are the external motivations to English learning of preparatory students. The core of art lies in emotion and teachers' investment of love and sincerity will touch the students who correspondingly demonstrate trust of teachers' care and trust of teachers themselves, and ultimately develop love and enthusiasm to the English course teachers deliver. Moreover, teaching style decides the glamour of art, and English teachers could decrease the anxiety of preparatory students in English learning by means of graceful pronunciation and lower-level language input. In order to arouse students' active participation in class activities and achieve resonation between teachers' teaching and students' learning, teachers could apply certain humorous ways, such as singing an English song to animate the class, questioning students to discover and correct mistakes, praising the ones who give correct answers, satisfying students' sense of accomplishment in English learning, and improving their self-confidence.

\subsection{Draw English Learning Methods from Antecedent Knowledge and Experience}

In the early 19th century, European linguists have set up historical comparative linguistics, which opened an age of comparison of branch languages and paved a way for mastering a new language based on familiar language experience and methods [3]. Though Chinese and English don't belong to the same branch in language family, it is commonly admitted that the large quantity of researches on Chinese and English comparison and their fruitful 
outcomes by Chinese language experts and scholars, are the effective methods to improve English learning quality [4]. However, there are 53 native ethnic languages in our nationalities university, and Chinese for some students is used as the second language and English as the third language; therefore, there are no distinguished research outcomes in comparison between English language and ethnic languages in nationalities universities.

Students spend the largest amount of time, besides their native language learning, in learning Mathematics, which is considered as an applied subject and a language as well. It's natural for us to wonder how to apply the methods of solving Mathematics problems to English learning. In fact, the learning methods of English sentence- structure concepts are identical to that of mathematical concepts, the mnemonic system of English and the methods of English problem solution are both identical to those of Mathematics [5,6].

\section{Conclusion}

In this essay, we have made an analysis and investigation of English learning barriers of minority preparatory students, and meanwhile, we attempt to furnish some effective methods of English learning for preparatory students to overcome the barriers of English learning in the following aspects, for example,

(1) Strengthen the communications among preparatory students, boost the integration of ethnic cultures and overcome the psychological conflicts

(2) Assist preparatory students to overcome the language barriers in accordance with their pronunciation features
(3) Take advantage of their ethnic languages and customs to enlarge English vocabulary

(4) Draw English learning methods from antecedent knowledge and experience

(5) Research teaching methodology and boost the art of teaching course

\section{Acknowledgements}

This work is supported by the independent fund of central universities ZJ12RWYBO, 2012 Dalian humanities and social science research project funding and Dalian Nationalities University education fund, and the State Ethnic Affairs Commission education fund.

\section{References}

[1] Jiuyi Shi and Wujia Zhu, Education and Introduction Analogy Association, Jiangsu Education Press, 1989.

[2] Keyong He, Research on English Teaching in Nationalities University, The Central University of Nationalities Press, 2007.

[3] Lifei Wang, Modern Teaching Method for Foreign Languages, Shanghai Education Press, 2000.

[4] Guoqiang Chen, A Contrastive Analysis of English-Chinese Conceptual Structures, Shanghai Foreign Language Education Press, 2008.

[5] JFuxia Li and Lidong Wan, "The Discussion of English Language Study and Mathematical Thinking”, Education Science, Vol. 26(1), 43-46, 2010.

[6] Fuxia Li and Lidong Wang, “The Application of Analogy and Transportation Method in English and Mathematics Teaching”, Education Science, Vol. 23(3), 29-30, 2007. 